LA -5108

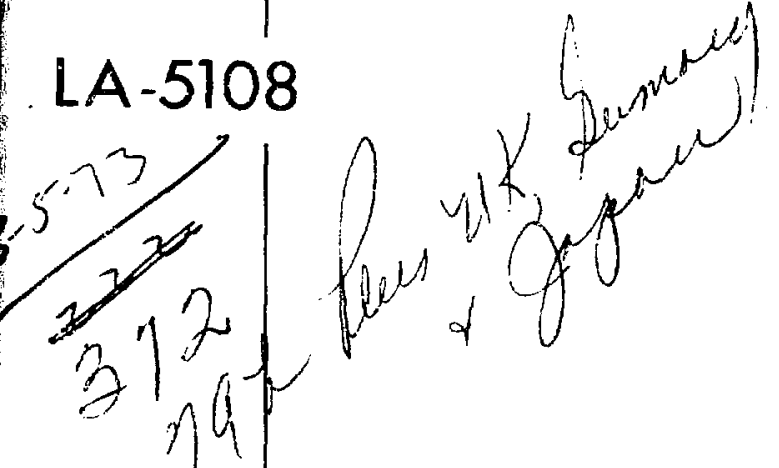


This report was prepared as an account of work sponsored by the United States Government. Neither the United States nor the United States Atoric Energy Commission, nor any of their employees, nor any of their contrac. tors, subcontractors, or their employees, makes any warranty, express or implied, or assumes any lega! liability or responsibility for the accuracy, completeness or usefuiness of any information, apparatus, product or process disclosed, or represents that its use would not infringe privateiy owned rights.

Printed in the United States of America. Available from

National Technical Information Service

U. S. Department of Commerce

5285 Port Roval Road

Springfield, Virginia 22151

Price: Printed Copy \$3.00; Microfiche \$0.95 
LA-5108

UC. $89 \% \mathrm{~K} / \mathrm{L}$

ISSUED: February 1973

\title{
Determination of Total Amount of Volatiles in Mixed-Oxide Reactor Fuel Pellets
}

by

\author{
Donald E. Vance \\ Mlaynard E. Smith \\ Glenn R. Waterbury
}

This work was sponsored by the Fuels and Materials Branch of the Division of Reactor Development and Technology of the United States Atomic Energy Commission. 


\title{
DETERMTNATION OF TOTAL AMOUNT OF VOLATILES
}

\section{IN MIXED - OXIDE REAC'TOR FUEL PLLLETS}

\author{
by
}

Donald E. Vance, Maynard E. Smith, and Glenn R. Waterbury

\begin{abstract}
A BSTRACT
Mixed-oxide reactor fuel pellets are heated inductively to $1600^{\circ} \mathrm{C}$ in a vacuum extraction apparatus to evolve the adsorbed volatiles which are measured volumetrically. Water vapor in the volatiles is removed by $\mathrm{Mg}\left(\mathrm{ClO}_{4}\right)_{2}$ dessicant, and the remaining gases are collected using a Toeppler pump. The pressure, volume, and temperature of the collected gases are measured, and the volume at standard conditions is calculated. The total amounts of volatiles measured other than water ranged between 0.020 and $0.059 \mathrm{~cm}^{3} / \mathrm{g}$ for one lot of samples. A mass spectrometric study of the volatiles evolved from 200 to $1800^{\circ} \mathrm{C}$ identified $\mathrm{H}_{2}, \mathrm{He}, \mathrm{CO}, \mathrm{CO}_{2}, \mathrm{~N}_{2}, \mathrm{NO}, \mathrm{O}_{2}$, and Ar.
\end{abstract}

\section{INTRODUCTION}

A property of sintered mixed oxides important to their use as reactor luels is the quantity of gas, including water vapor, evolved at reactor operating temperatures. Because of the small quantities of volatiles generally found in sintered fuel pellets, a sensitive method was required. A vacuum extraction $s_{j}$ stem having a small calibrated volume for measuring the evolved gases without excessive dilution or contamination was desisned and tested. The design requirements of the vacuum extraction system precluded the simultaneous determination of water with the other volatiles because the large-diameter tubing and valves, water-cooled pumps, and large-volume glassware presented considerable opportunity for adsorption of water vapor before it could be measured. Consequently, the water was determined separately. ${ }^{l}$

\section{I1. APPARATISS AND REAGENTS}

A. Apparatus

Bucket, made from 4-mil tungsten foil, 1 in. high. 3/8-in. o.d. (Fig. 1).

Calibrated sample tube, made of graduated glass tubing, approximately 1.25-ml total volume (Fig. 2). Calibrate by weighing the amounts of mercury required to fill to each graduation mark and calculating the respective volumes.

Chain, gold, with welded links approximately $1 \mathrm{~mm}$ long.

Chain, platirium, 2-in.-long welded links made from 0.010-in. platinum wire.

Desiccant tube, borosilicate glass, filled with anhydrous magnesium perchlorate ( 6 to $8 \mathrm{mesh}$ ) and plugged with glass wool in each end to contain the reasent dust.

Diflusion pumps, glass, two required, Consolidated Vacuum Corporation (CVC), type GHG-15, or equivalent pump which will continue to punip with relatively high forepressures. Water-cooled, rather than nitrogen-cooled, condensers were used on these pumps to avoid condensation of volatiles from the pellets, and gold foil was placed in the enirance arm of the condenser nesrest the induction furnace as a barrier to bark-diffusion of mercury vapor into the furnace. 


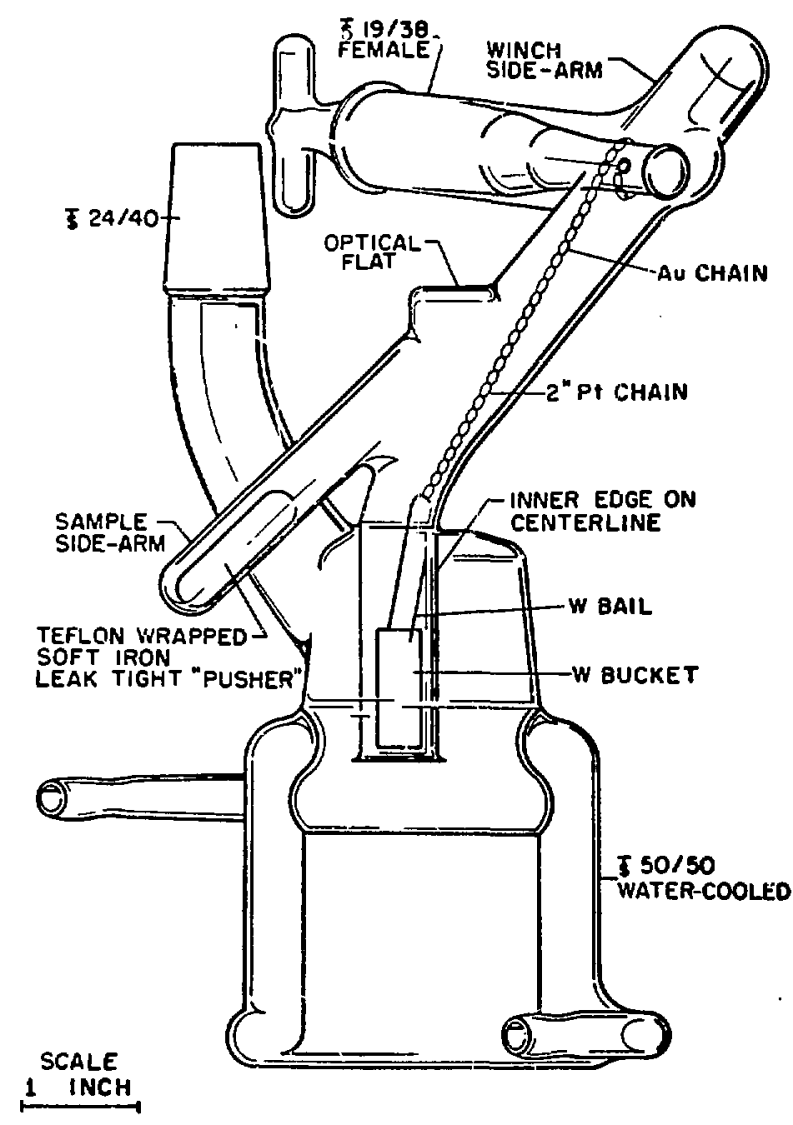

Fig. 1. Sample manipulator.

Diffusion pump, metal, CVC type MHG-180, or equivalent.

Electric timers, 30-sec, two required, Ind 1 strial Timer Corporation. of equivalent. Wired so that one timer controls the vacuum half of the Toeppler pump cycle and the other alternately controls the pressure half of the cycle.

Furnace adapter, borosilicate glass (Fig. 3 ).

Furnace tube, fused-silica (Fig. 4). The furnace tube is surrounded by a water jacket in which the wire indiction coil is inserted. The outer tube is seaied to the induction coil terminal bloaks with epoxy cement to make a water-tight seal and the inner tube (furnace tube) is sealed with Viton O-rings as shown. This furnace design yielded the lowest apparatus background of several designs tested.
Gloved enclosure, suitable for handling plutonium oxide. The enclosure contains only the induction furnace tube and furnace fittings.

Induction generator, $25 \mathrm{~kW}$, LASL drawing No. $26 \mathrm{Y}-76681$, or equivalent.

Mass spectrometer, Consolidated Electrodynamics Corporation, Model 21-620, or equivalent.

McLeod gauge, constructed of borosilicate glass tubing of the same diameter used in the sample tube (Fig. 2).

Pressure controls, Mercoid Corporation, or equivalent, three required to turn off diffusion pump heaters in case of cooling-water failure.

Regulator, high pressure, Victor Equipment Compary, or equivalent.

Regulator, low pressure, 0 to 50 in. of water range, Moore Products Company, Model 40-2, or equivalent regulating device.

Regulator, low pressure, Matheson Company, Model 2403-M2, or equivalent.

Sample loader, borosilicate glass (Fig. S).

Sample manipulator, borosilicate glass (Fig. 1).

Sight glass, borosilicate glass (Fig. 3 ).

Solenoid valves, Skinner Electric Valve Division, one No. V5D3870 or equivalent and one V $5 \mathrm{Dl} E 80 \mathrm{CR}$ or equivalent required; Automatic Switch Company, one No. $827616 \mathrm{R}$ or equivalent required.

Thermometer, mercury, two required, one having a range of -10 to $+510^{\circ} \mathrm{C}$, and one suitable for measuring ambient temperature.

Toeppler pump, $250 \mathrm{ml}$, Eck and Krebs Scientific Laboratory Class A pparatus, Incorporated, or equivalent.

Tongs, stainless steel, 12 in. long, modified so that the tip s spread outward when the handle is compressed. to remove and replace the crucible in the induction furnace.

Tubing, 304 stainless steel, 0.75-in. o.d. , for construction of vacuum manifold.

Vacuum gauges. two required, NRC Equipment Corporation. Type 701 , or equivalent. 


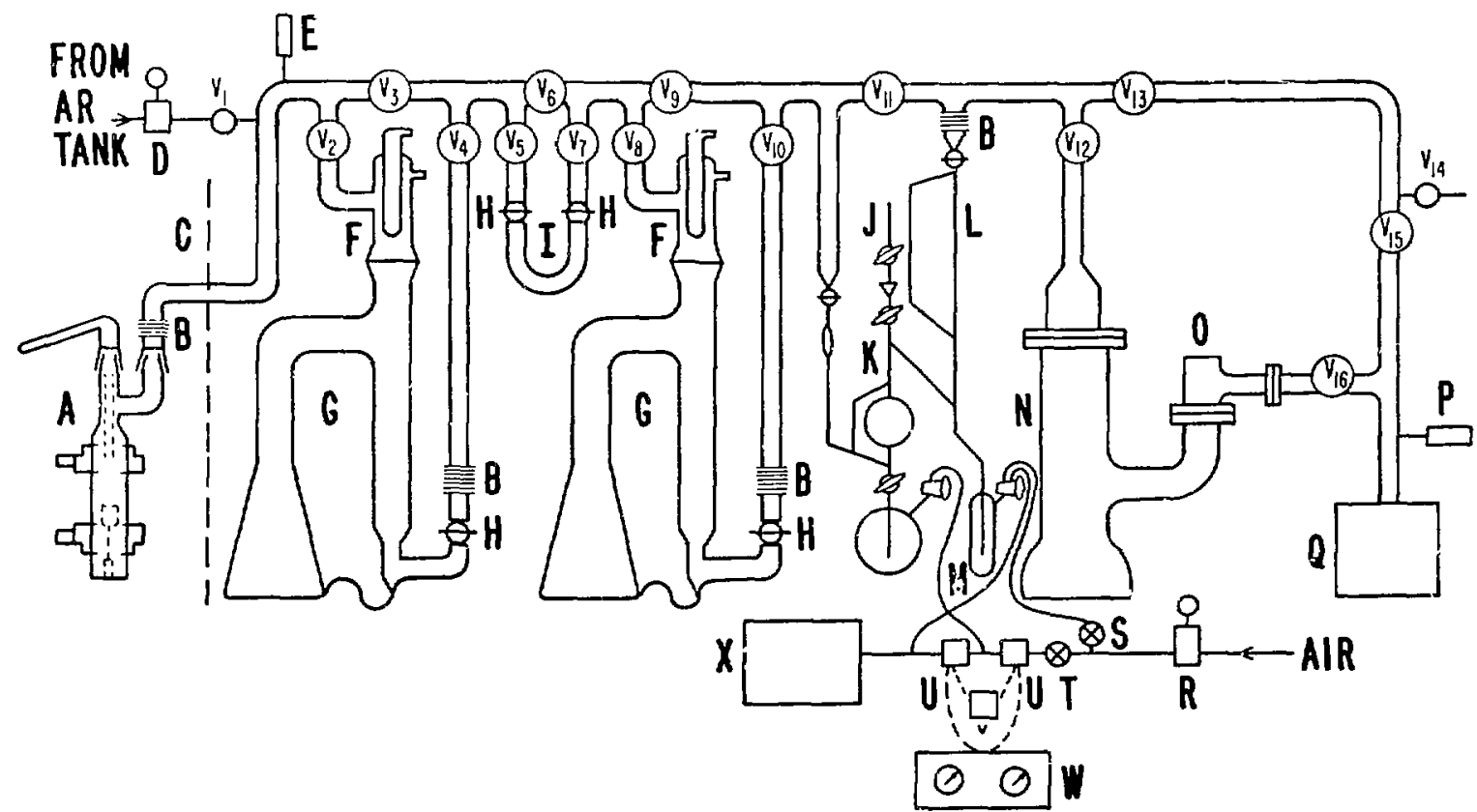

Fig 2. Vacuum extraction system. A, induction furnace assembly; B, monel bellows; C, wall of gloved enclosure; D, low pressure regulator, 0 to $50 \mathrm{in}$. of water; $\mathrm{E}$, vacuum gauge thermocouple; $F$, water-cooled condensers; $G$, glass diffusion pumps; H, $28 / 12$ semi-ball joints; $\mathrm{I}, \mathrm{M}_{\mathrm{ig}}\left(\mathrm{C} 1 \mathrm{O}_{4}\right)_{2}$ trap; $\mathrm{J}$, calibrated sample tube; $\mathrm{K}$, Toeppler pump; L. McLeod gauge; $\mathrm{M}$, mercury reservoir; $N$, metal diffusion pump; $O$. water-cooled baffle; $P$, vacuum gauge thermocouple; $Q$, mechanical forepump; $R$, low pressure regulator; $S$, needle valve; $T$, needle valve, $U$, solenoid valves; $V$, cycle counter; $W$, Toeppler pump timers; $X$, mechanical vacuum pump; V 1 and V14, Hoke valves No. 4551Q4M; V2 through V13, V15 and V16, stainless steel bellows valves.

Vacuum manifold, stainless steel tubing, valves, bellows . and fittings; welded joints throughout (Fig. 2). Tees were drawn in the tubing, using the method described by Ruess, ${ }^{2}$ to permit $100 \%$ penetration in the welded joints and to provide optimum gas flow characteristics.

Vacuum pumps, mechanical, W. M. Welch Manufacturing Company, Model $1405 \mathrm{H}$, and Cenco Hyvac, Catalog No. 91105.

Valve, bellows, stainless steel, Heraeus Englehard Vacuum. Incorporated, or equivalent, 14 required.

Valve. Hoke No. $4551 \mathrm{l}-4 \mathrm{M}$ or equivalent, two required.

Variable transformers, 10-A, two required for operation of the glass diffusion-pump heaters.

\section{B. Reagents}

Argon, tank.

Grease, silicone, Dow-Corning high-vacuum.

Magnesium perchlorate, anhydrous, reagent grade.
Mercury, triple-distilled

Wax, Apiezon W.

\section{SAMPLE PREPARATION}

Inspect the sample for obvious impurities such as lint, and remove any foreign material. Because pellei storage conditions are not yet rigidly specified, analyze sample pellets as received without further preparation. It has become obvious, however, from this and other work, ${ }^{1}$ that storage under dry conditions would alleviate problems in the use of the pellets as reactor fuel, and also simplify the analytical methods for measuring volatiles and water.

\section{RECOMMENDED PROCEDURE}

CAUTION: Health and safety rules for handling of radioactive materials must be rigidly followed, and adequate protection for the operator must be ensured by the use of suitable gloved enclosures and protective clothing. 


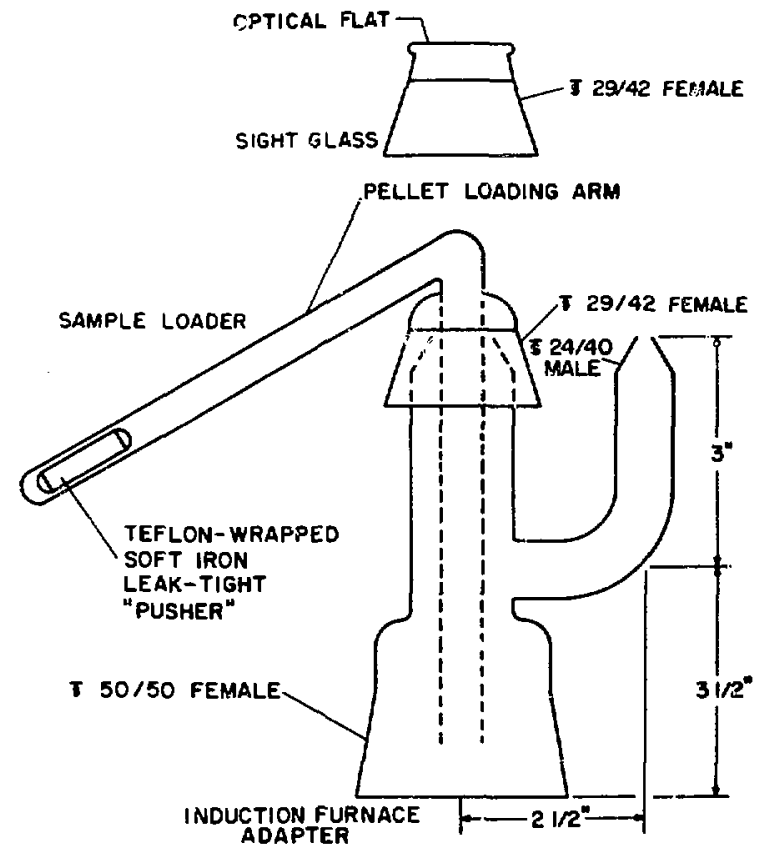

Fig. 3. Induction furnace adapter, sample loader, and sight glass.

1. Keep the apparatus under forepump vacuum at all times when not in use. Turn on the diffusion pumps about $12 \mathrm{~h}$ before samples are to be analyzed.

2. Isolate the furnace tube by closing valves V2 and V3 (Fig. 2), and disconnect the sample loader while flushing the furnace with argon through valve $\mathrm{V} 1$.

3. Fill the loading arm with the fuel pellets to be analyzed and reconnect the sample loader to the furnace, sealing the jcint with silicone grease.

4. Evacuate the furnace by closing valves $\mathrm{V} 1, \mathrm{~V} 4, \mathrm{~V} 5, \mathrm{~V} 7, \mathrm{~V} 8, \mathrm{~V} 10, \mathrm{~V} 12$, and $\mathrm{V} 16$, opening valves V15, V1j, V11, V9, and V6, and slowly opening valve $\mathrm{V} 3$ so as not to cause violent agitation of the mercury in the Toeppler pump. When the thermocouple gauge, $P$, indicates a pressure of 100 microns or less, close valves V3, V6, V9, V13 and $\mathrm{V} 15$, and open valves $\mathrm{V} 16, \mathrm{~V} 12, \mathrm{~V} 10, \mathrm{~V} 8, \mathrm{~V} 7$. $\mathrm{V} 5, \mathrm{~V} 4$, and $\mathrm{V} 2$.

5. Heat the empty crucible slowly to increase its temperature to $1600^{\circ} \mathrm{C}$ during 4 to $6 \mathrm{~h}$.

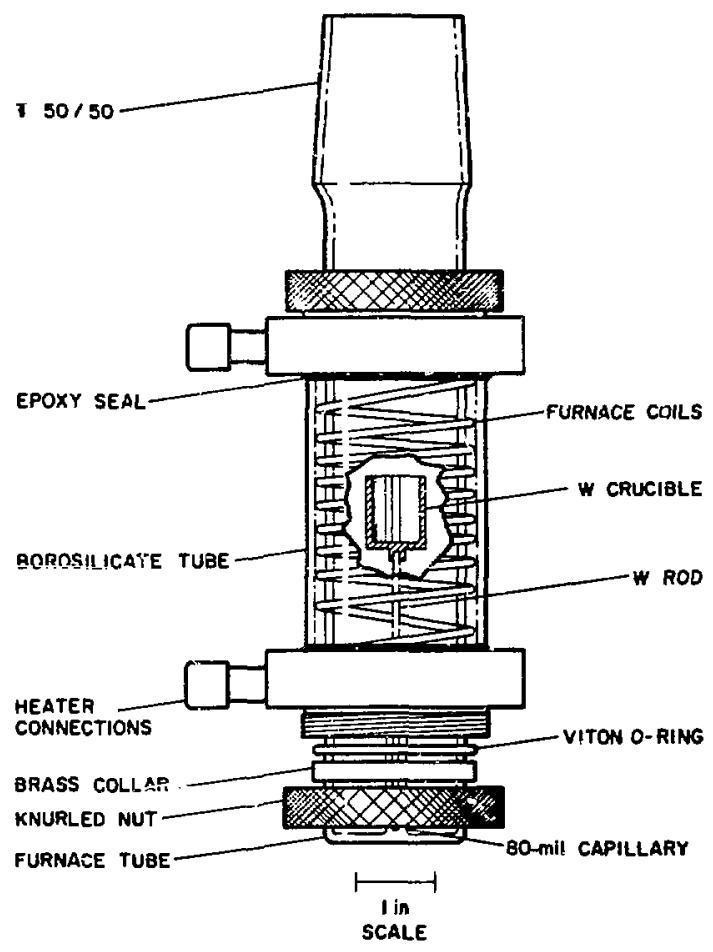

Fig. 4. Induction furnace and fused-silica furnace tube.

6. Slowly open the three-way stopcock to allow air to enter the mercury reservoir, $M$, until mercury rises about halfway up the side-arm leading to the Toeppler pump.

7. Close valve V11 and start the Toeppler pump timers, W.

8. After about $35 \mathrm{~min}(70 \mathrm{cycles}$ of the Toeppler pump), close the stopcock above the reservoir bulb of the Toeppler pump with the mercury at the top of its cycle, and turn off the timers.

9. Allow more air to enter the reservoir, $M$, until the mercury reaches a suitable graduation on the sample tube, $\mathrm{J}$.

10. Record the temperature, volume, and difference in millimeters pressure hetween this level of mercury and the level of mercury in the McLeod gauge. 
11. Calculate the amount of gas irapped in the sample tube (apparatus background) using Eq. (1).

Volume at standard conditions $=\frac{P V}{2.782 \mathrm{~T}}(1)$ in which:

$\mathrm{P}=$ difference in millimeters pressure,

$\mathrm{V}=$ sample volume $\left(\mathrm{cm}^{3}\right)$, and

$\mathrm{T}=$ temperature of sample tube $\left({ }^{\circ} \mathrm{K}\right)$.

12. Repeat steps 6 through 10 until the apparatus background decreases to a stable value of less than $0.010 \mathrm{~cm}^{3}$ at standard temperature and pressure; turn off the induction generator and allow the crucible to cool co approximately room temperature.

13. Use a magnet to move the iron push-rod up the side arm of the sample loader until the first pellet drops into the crucible. Determine the gas evolved from the sample by repeating steps 6 through 11 while heating the srucible at $1600^{\circ} \mathrm{C}$.

i4. Subtract the amount of gas measured in Step 10 above to calcuiare the gas released from the pellet.

15. Alternate determinations of the apparatus background and samples.

\section{EXPERIMENTAL}

Reaction between the hot tungstein srucible and the water evolved from the fuel pellets was suspected of producing hydrogen which would cause an error in the results for the total volatiles. For this reason, the reaction was investigated by heating tungsten powder in a moist argon atmosphere and analyzing the argon for hydrogen contamination with a mass spectrometer. No reaction was detected after heating at $350^{\circ} \mathrm{C}$ for $45 \mathrm{~min}$, but hydrogen wo 3 detected in the argon after heating at $400^{\circ} \mathrm{C}$ for $20 \mathrm{~min}$ and also after heating at $500^{\circ} \mathrm{C}$ for $10 \mathrm{~min}$.

The compositions of the effluent gases from the fuel pellets at various temperatures were determined. To assure accurate temperatures, the power settings of the induction generator were calibrated by measuring the temperatures produced with either a mercury thermometer for the 200-to$500^{\circ} \mathrm{C}$ range or an optical pyrometer for higher temperatures. The thermometer was inserted through a 1-hole rubber stopper fitted into the top of the furnace tube with the thermometer bulb touching the bottom of the empty crucible in the furnace. The furnace was then evacuated and the temperature within the crucible rneasured as the generator power settings were changed. Power settings for each temperature of interest above $500^{\circ} \mathrm{C}$ were determined using a completely evacuated furnace fitted with a sight glass through which the femperatures were measured with an optical pyrometer. The empty crucible was heated slowly to prevent too rapid outgassing and subsequent deposition of tungsten oxides on the furnace walls.

The method selected as the most reliabie and convenient for handling the pellets for the tests at various temperatures utilized a manipulator (Fig. 1) to remove and replace the pellet in the crucible while maintaining the vacuum in the induction furnace tube. A fuel pellet was placed in the side-arm of the manipulator, the manipulator was placed on the furnace, and the apparatus was evacuated. The empty tungsten-foil bucket was then lowered into the crucible and both bucket and crucible were outgassed at $2000^{\circ} \mathrm{C}$. When repeated measurements showed the apparatus background at $2000^{\circ} \mathrm{C}$ to be low and reproducible, the bucket temperature was lowered to $200^{\circ} \mathrm{C}$ and held there until a stable apparatus background was attained at the lower temperature. The gas collected in the sample tube during the last measurement of the apparatus background was analyzed with a mass spectrometer.

The crucible was allowed to cool, and the bucket was raised to a position immediately below the sample side-arm. A magnet was ised to move the iron rod that pushed the pellet out of the sidea r'm so it would fall into the bucket. The bucket and pallet were then lowered into the crucible and heated to $200^{\circ} \mathrm{C}$. At the end of the heating period the yas collected in the sample tube was analyzed, using the mass spectrometer, for $\mathrm{K}_{2}, \mathrm{He}, \mathrm{CO}, \mathrm{N}_{2}$ (and $\mathrm{NO}$ ). $\mathrm{O}_{2}, \mathrm{Ar}$. and $\mathrm{CO}_{2}$. The percentage rom. position and number of micromoles of each gess were calculated after subtracting the apparatus background. The bucket and pellet were then raised into the side-arm of thite manipulator containing the winch, and the empty arucible heated to a temperature equivalent to a bicket temperature of 
$500^{\circ} \mathrm{C}$. The apparatus background at this temperature was determined. The bucket and pellet were lovered into the crucible and heated to $500^{\circ} \mathrm{C}$. This priscedure was repeated at $800,1000,1300,1600$ ani $1800^{\circ} \mathrm{C}$, and the collected gas samples from the empty crucible and from the crucible-plus-pellet at each temperature were analyzed with the mass spactrometer.

The amount of gas contributed by the bucket during the heating of the pellet was considered insignificant compared to the effluent variations between the individual peliets analyzed. At temperatures up to $1300^{\circ} \mathrm{C}$ (Table I) the principal comporient of the evolved gas was $\mathrm{H}_{2}$, and $\mathrm{CO}$ was the principal component at 1600 and $1800^{\circ} \mathrm{C}$.

The tungsten-water reaction might produce some of the hydrogen coilected at $500^{\circ} \mathrm{C}$. A large fractiun of the water would evolve at $200^{\circ} \mathrm{C}$ and not react with the crucible at this temperature. Because essentially all of the remaining water was evolved at the end of the $500^{\circ} \mathrm{C}$ heating period ${ }^{l}$ ( 35 $\min$ at $200^{\circ} \mathrm{C}$ and $35 \mathrm{~min}$ at $500^{\circ} \mathrm{C}$ ), it is uniikely that any hydrogen collected at higher temperatires comes from water. If all of the hydrogen measured at $500^{\circ} \mathrm{C}$ was from this source, which is unlikely because of the evaporation of the water and the slow rate of reaction wiih the tungsten, the error in the total volatiles collected would be approximately $6 \%$. A maximum of one-fourth of the total hydrogen collected conceivably could derive from the water, but most of the evolved hydrogen probably had been alsorbed from the sintering furrace atmosphere during pellet manufacture. ${ }^{3}$

The amouni of carbon monoxide increased riapidly at temparatures above $1300^{\circ} \mathrm{C}$. This inciease was probably ceused by reduction of the uranium-plutonium dioxide by carbon impurities that reportedly average about $50 \mathrm{ppm}^{4}$ in the fuel material. The amount of carbon monoxide evolved at $1800^{\circ} \mathrm{C}$ could cause an error in the calculated reactor conditions if these calculations were based on total volatile measurements taken at $1600^{\circ} \mathrm{C}$.

Analysis for volatiles at temperatures higher tizan $1800^{\circ} \mathrm{C}$ does not appear feasible. One peillet heated to $1900^{\circ} \mathrm{C}$ for $35 \mathrm{~min}$ and then to $2100^{\circ} \mathrm{C}$ apparently began to volatilize at $1900^{\circ} \mathrm{C}$ as evidenced by a deposit formed on the walls of the induction furnace. At $2100^{\circ} \mathrm{C}$ the deposition wegan to cause excessive heating of the furnace tube O-ring seal. When all pellet particles remaining in the iurnace crucible were weighed, the loss of pellet material by vaporization wa's approxiinately $60 \%$.

The amount of nitric oxide evolved from the pellets was not determined because a suitable standard was not available to determine the sensitivity of the mass spectrometer. If the respective sensitivities of the mass spectrometer were identical, the quaritities of evolved nitric oxide and argon were about equal. These amounts would not cause significant error in the quantities of nitrogen reported.

From the results of this investigation, a temperature of 1600 to $1800^{\circ} \mathrm{C}$ was selected as optimum for the evolution of volatiles. If the quantities of water in these pellets increase to levels that interfere seriously in the measurement of total volatiles because of the hydrogen produced, the use of crucible materials other than tungsten will be investigated to avoid the tungsten-water reaction. A tungsten crucible and a temperature of $1600^{\circ} \mathrm{C}$ are used at the present tirne to assure uniformity in results among various laboratories.

\section{RELIA.BILITY}

The precision and accuracy of this method could not be determined because of the lack of suitable standards and because of heterogeneity in volatiles content among individual pellets from one lot. The pooled standard deviation obtained by seven laboratories for the analysis of one lot of uranium-plutonium dioxide pellets by this and similar methods was $0.012 \mathrm{~cm}^{3} / \mathrm{g}$ at standard temperature and pressure. ${ }^{4}$ This precision estimate includes the between-pellet and the analytical measurement variabilities.

\section{CONCLUSIONS}

A vacuum extraction method was developed for the determination of total volatiles other than water in sintered FFTF reactor fuel pellets of uranium-plutonium dioxide. A fuel pellet is heated inductively to $1600^{\circ} \mathrm{C}$ in a tungsten crucible for approximately $35 \mathrm{~min}$. The evolved water is removed with $\mathrm{M}_{\mathrm{H}}\left(\mathrm{C} 1 \mathrm{O}_{4}\right)_{2}$ and the other gases are collected 
TABLE I

\section{COMPOSITION OF EFF LUENT}

\begin{tabular}{|c|c|c|c|c|c|c|c|c|}
\hline$\left({ }^{\mathrm{T}} \mathrm{C}\right)$ & $\begin{array}{c}\text { Tot:l } \\
\text { Micromules } \\
\end{array}$ & $\begin{array}{r}\mathrm{H}_{2} \\
(\%) \\
\end{array}$ & $\begin{array}{r}\mathrm{He} \\
(\%) \\
\end{array}$ & $\begin{array}{r}\mathrm{O}_{2} \\
(\%) \\
\end{array}$ & $\begin{array}{r}\text { Ar } \\
\left(m_{0}\right) \\
\end{array}$ & $\begin{array}{l}\mathrm{CO}_{2} \\
(\%)\end{array}$ & $\begin{array}{r}\mathrm{CO} \\
(\%)\end{array}$ & $\begin{array}{l}\mathrm{N}_{2} \& \mathrm{NC} \\
\quad\left(\mathrm{N}_{0}\right) \\
\end{array}$ \\
\hline 200 & 0.041 & 30.7 & 0 & 2.4 & 0.4 & 8.2 & 28.6 & 29.7 \\
\hline 500 & 0.487 & 68.7 & trace & 1.7 & 0.1 & 4.9 & 10.6 & 14.0 \\
\hline 800 & 0.625 & 74.9 & 0.3 & 0.3 & trace & 0.7 & 18.7 & 5.4 \\
\hline 1000 & 0.384 & 67.5 & 0.2 & 0.3 & trace & 0.4 & 24.7 & 6.8 \\
\hline 1300 & 0.457 & 52.9 & 1.1 & 0.4 & trace & 0.5 & 35.6 & 9.5 \\
\hline 1600 & 1.294 & 1.8 & 0.7 & 0.6 & 0.1 & 0.2 & 95.2 & 1.4 \\
\hline 1800 & 2.644 & 0 & 0.3 & 0.2 & 0.1 & 0.1 & 99.3 & 0 \\
\hline
\end{tabular}

by a Toeppler pump and measured. The amounts of gas released by three pellets analyzed were $0.059,0.030$, and $0.022 \mathrm{~cm}^{3} / \mathrm{g}$ of pellet material. Mass spectrometric analysis of the gas collected after heating pallets to various temperatures showed the presence of $\mathrm{H}_{2}, \mathrm{He}, \mathrm{CO}, \mathrm{N}_{2}, \mathrm{NO}, \mathrm{O}_{2}, \mathrm{Ar}$, and $\mathrm{CO}_{2}$. Increasing amounts of carbon monoxide released at temperatures from 1300 to $1800^{\circ} \mathrm{C}$ indicate that $1800^{\circ} \mathrm{C}$ may be a more suitable tempeature for analysis than the previously-specified $1600^{\circ} \mathrm{C}$. Analysis above $1800^{\circ} \mathrm{C}$ does not appear feasible because of volatilization of the fuel pellets.

The accuracy of the deternination of the volatiles would possibly be improved if the fuel pellets were stored in a desiccator after removal from the sintering furnace during manufacture. The pellets rapidly adsorb some moisture from the air ${ }^{1}$ and it is later released during analysis for volatiles. The moisture may be reduced by the hot tungsten crucible to hydrogen and cause an erroneous high measurement of total volatiles evolved. The extent of this reaction during volatiles analysis is unknown but should not be appreciable with pellets containing $3 \mu \mathrm{g}$ of water or less per gram of pellet material. During analysis, the tungsten crucible is heated to $1600^{\circ} \mathrm{C}$ in approximately $1 \mathrm{~min}$. The rapid outgassing of water from the fuel pellet, combined with the high pumping speed of the vacuum apparatus, may cause the extent of the tungsten-water reaction to be insignificant.

\section{ACKNOWLEDGMENTS}

The authors thank Gerald C. Swanson for his assistance in obtaining some of the data and Charles F. Metz, under whose supervision this work was accomplished.

\section{REFERENCES}

1. D. E. Vance, M. E. Smith, and G. R. Waterbury, "Determination of Water Evolved from FFTF Reactor Fuel Pellets, " Los Alamos Scientific Laboratory report LA-4681 (July 1971).

2. H. M. Ruess, J. D. Newkirk, and N. G. Wilson, 'Tee Drawing for Tubular Vacuum Systems," Los A lamos Scientific Laboratory report LA-3517 (March 1966).

3. W. H. Pechin and R. A. Bradley, "Fuels and Materials Development Program Quarterly Progress Report for Period Ending December 31 , 1969, "Oak Ridge National Laboratory report ORNL-4520 (May 1970).

4. J. E. Rein, R. K. Zeigler, and C. F. Metz, "LMF BR/FFTF Fuel Development Analytical Chemistry Program (Phase II), "Los Alamos Scientific Laboratory report LA - 4407 (March $1970)$. 